\title{
DESAFIOS DO TRABALHO DE EDUCADORAS SOCIAIS EM CASAS DE ACOLHIMENTO
}

\author{
DESAFÍOS DEL TRABAJO DE LOS EDUCADORES SOCIALES EN INSTITUCIONES \\ $D E A C O G I D A$
}

\section{CHALLENGES OF THE WORK OF FEMALE SOCIAL EDUCATORS IN SHELTERS}

\author{
Eiza Nádila BASSOLI ${ }^{1}$ \\ Vanessa Cartherina Neumann FIGUEIREDO ${ }^{2}$
}

\begin{abstract}
RESUMO: Este estudo analisa as vivências de prazer e sofrimento no trabalho de educadoras sociais em Casas de Acolhimento no Pantanal Sul-Mato-Grossense. Baseado na teoria da Psicodinâmica do Trabalho, foi analisado o sofrimento derivado do choque entre as normatizações organizacionais e as situações laborais reais experienciadas no atendimento a crianças e adolescentes. Nove profissionais de duas instituições públicas foram entrevistadas, cujas narrativas foram ponderadas através da Análise de Sentido. Os resultados apontam para o uso constante de inteligência prática diante de condições materiais e capacitações insuficientes, relações institucionais desrespeitosas, falta de suporte emocional-afetivo e autoaceleração pela sobrecarga de trabalho imposta. A identificação com as tarefas socioeducativas e a satisfação com o desenvolvimento dos acolhidos foram os aspectos citados propulsores de realização. Conclui-se ser necessário o reconhecimento da profissão e da importância da educação social para a reintegração segura dos acolhidos na família de origem ou lar adotivo.
\end{abstract}

PALAVRAS-CHAVE: Educador social. Sofrimento. Abrigo. Psicodinâmica.

RESUMEN: Este estudio analiza las experiencias de placer y sufrimiento en el trabajo de los educadores sociales en las Casas de Recepción en el Pantanal, Brasil. Basado en la teoría psicodinámica del trabajo, se analizó el sufrimiento derivado de la brecha entre las normas organizativas y situaciones reales experimentadas en el cuidado de niños y adolescentes. Nueve educadoras de dos instituciones públicas fueron entrevistadas. Los resultados apuntan al uso constante de la inteligencia práctica, condiciones materiales y la formación insuficiente, relaciones institucionales irrespetuosas, falta de apoyo emocional-afectivo y autoacelación debido a la sobrecarga impuesta. La identificación con las tareas socioeducativas y la satisfacción con el desarrollo de los acogidos fueron los aspectos gratificantes. Se concluye que es necesario reconocer la profesión y la importancia de la educación social para lograr la reintegración segura de los acogidos, en la familia de origen o adoptiva.

PALABRAS CLAVE: Educador social. Sufrimiento. Abrigo. Psicodinamica.

\footnotetext{
${ }^{1}$ Universidade Federal de Mato Grosso do Sul (UFMS), Corumbá - MS - Brasil. Mestre em Educação. ORCID: https://orcid.org/0000-0003-4822-4049. E-mail: bassolien@gmail.com

${ }^{2}$ Universidade Federal de Mato Grosso do Sul (UFMS), Corumbá - MS - Brasil. Professora Associada no Curso de Psicologia, no Programa de Pós-Graduação em Educação e no Programa de Pós-Graduação em Estudos Fronteiriços. Doutora em Saúde Coletiva (UNICAMP). ORCID: https://orcid.org/0000-0002-2114-6493. E-mail: vanessa.figueiredo@ufms.br
}

RIAEE - Revista Ibero-Americana de Estudos em Educação, Araraquara, v. 15, n. esp. 3, p. 2396-2410, nov., 2020. E-ISSN: 1982-5587 
ABSTRACT: This paper analyzes the experiences of pleasure and suffering in the work of female social educators in shelters in the Mato Grosso do Sul Pantanal, Brazil. Based on the Psychodynamic of Work, the suffering derived from the shock between organizational norms and the real work situations experienced in the care of children and adolescents was analyzed. Nine professionals from two public institutions were interviewed, whose narratives were weighted through meaning analysis. The results point to the constant use of practical intelligence in the face of insufficient material conditions and training, disrespectful institutional relations, lack of emotional-affective support and self-acceleration due to the imposed work overload. The identification with the socio-educational tasks and the satisfaction with the development were the aspects mentioned as achievement drivers. It is concluded that it is necessary to recognize the profession and the importance of social education for the safe reintegration of those welcomed in the family of origin or adoptive.

KEYWORDS: Social educator. Suffering. Shelter. Psychodynamics.

\section{Introdução}

O trabalho dos educadores sociais que atuam em Casas de Acolhimento configura-se como uma atividade de extrema relevância para as crianças e adolescentes institucionalizados e que em razão de variáveis situacionais diversas vivenciaram experiências de ameaças e/ou violações, como negligências, maus-tratos, crueldades e abusos (BRASIL, 1990; BRASIL, 2009). Assim, quando pais e responsáveis não conseguem prover o bem-estar de seus dependentes, passa a ser incumbência do Estado a execução de programas de apoio temporário e a aplicação de medidas de proteção especial, como a do Acolhimento Institucional, na tentativa de se evitar a (re)incidência da violência.

Conforme normatizado pelo Serviço de Alta Complexidade do Sistema Único de Assistência Social (SUAS), as Casas de Acolhimento devem ofertar abrigo em um ambiente similar ao de uma residência, com sala de estar, de jantar e para reuniões, ambiente de estudo, área externa e espaço para os acolhidos guardarem seus pertences. Ganha importância a assistência personalizada com respeito à identidade e à história de vida de cada um, a assistência a grupos de no máximo 20 usuários e a composição de uma equipe constituída minimamente por um coordenador, dois profissionais com formação de nível superior (preferencialmente um psicólogo e um assistente social), um educador social para até 10 usuários/turno e um auxiliar de educador (ambos com ensino médio completo) (BRASIL, 2006; 2009).

Dentro deste contexto institucional, os educadores sociais se tornam responsáveis pela aplicabilidade da educação não formal, e assumem o lugar temporário de referência afetiva em substituição aos responsáveis legais, de modo a acompanhar as crianças e adolescentes dentro e fora da instituição. Suas tarefas de cuidado e educação incluem providenciar alimentação, 
higiene e proteção; arranjar o ambiente e a oferta de atividades em conformidade com a faixa etária; acompanhar os usuários em tratamentos de saúde e na escola; auxiliar nas tarefas; orientar na classificação de registros e lembranças que preservem sua história de vida; apoiar nas dificuldades cognitivas e emocionais; promover o desenvolvimento da autoconfiança e da identidade; e preparar os acolhidos para se desligarem da instituição (BRASIL, 2009).

Além das atribuições anteriormente descritas, também se configura como um compromisso do educador social a viabilização da construção/reconstrução de concepções de mundo mais justas, com o intuito de empoderar os acolhidos e levá-los a novas formas de pensar e agir, tornando-os mais ativos e participativos nos processos socioculturais e políticos decisórios, através do ensino de seus direitos (PEREIRA, 2016). É através de suas atividades diárias que os profissionais legitimam o respeito aos direitos humanos e contribuem na superação das marcas deixadas pelas ameaças/riscos sociais, de forma a favorecer a (re)construção de um futuro mais esperançoso (FERREIRA; SANTOS, 2019).

Ainda que estudos de Lima (2011) e Cavalcante e Corrêa (2012) tenham constatado o gosto pelas tarefas de arrumar a casa, alimentar e higienizar os acolhidos, vários são os desafios desta complexa ocupação, como ter de resolver conflitos e lidar com problemas organizacionais sem receber o devido reconhecimento, situações geradoras da sensação de inutilidade e de fracasso. A dificuldade de lidar com crianças hostis e adolescentes desafiadores (LEMOS; MORAES; ALVES; HALPERN; LEITE, 2014), a demanda de cuidar, apoiar e afirmar laços estáveis promotores de proteção e de desenvolvimento junto a cada usuário (GOLIN; BENETTI, 2013; TINOCO; FRANCO, 2011), o grande número de acolhidos frente à quantidade de profissionais disponíveis, são aspectos do trabalho que se traduzem em sobrecarga e desgaste emocional (HALPERN; LEITE; MORAES; 2015; LIMA, 2011).

Ao mesmo tempo em que são valorizadas as afeições no momento de recepção dos usuários, Medeiros e Martins (2018) e Teixeira e Villachan-Lyra (2015) indicam que o momento do desacolhimento não tem ganhado suficiente atenção, necessitando ser disponibilizado suporte emocional à equipe, pelo sentimento de abandono que emerge e que pode vir a se tornar um empecilho no desenvolvimento do apego. Além disso, para ser viável a meta de reintegração social, Costa, Santos, Santos e Lima (2018) apontam a necessária atuação junto às famílias, de modo a compreender a situação de vulnerabilidade socioeconômica e orientar no acesso a políticas assistenciais e de emprego, oportunizando, dessa forma, a promoção de espaços domésticos protetores.

Embora seja indispensável a oferta de supervisão, apoio e capacitação, a regulamentação falha da profissão (MANICA, 2017) e a falta de reconhecimento da importância das ações 
socioeducacionais para a transformação do cenário de exclusão e de vida dos acolhidos (PEREIRA, 2016) colaboram para a invisibilidade das demandas específicas de educadores sociais. Levando em conta a ampla brecha entre as normatizações e prescrições a serem postas em prática e a realidade caracterizada por situações de trabalho insatisfatórias para atender pessoas em situação de violação de direitos, este artigo analisa as vivências de prazer e sofrimento de educadoras sociais no trabalho de atendimento infanto-juvenil em Casas de Acolhimento no Pantanal Sul-Mato-Grossense.

\section{Conceitos norteadores da pesquisa}

Para analisar as vivências de prazer e de sofrimento psíquico das educadoras sociais, adotou-se como referencial teórico a Psicodinâmica do Trabalho. Voltada para a compreensão das relações entre trabalho e processos de subjetivação, a análise da ligação do sujeito com a organização do trabalho permite compreender os processos de regulação psíquica canalizadores da experienciação de prazer e sofrimento no contexto laboral.

Se por um lado a ação de trabalhar cumpre função construtiva e promove o desenvolvimento da inteligência, de habilidades, viabiliza a expressão da subjetividade no mundo externo e possibilita o alcance da satisfação e prazer através de ressignificação do sofrer via sublimação, o impedimento de transformar o trabalho pode fazer o sofrimento culminar em adoecimento ou patologias, dependendo da relação intersubjetiva estabelecida com a organização do trabalho, condições materiais e entre as pessoas (DEJOURS, 2013). Ao impor rigidamente regras, valores e metas a serem seguidas sem a possibilidade de negociação, a lógica organizacional prescrita acaba por impedir exatamente a expressão da subjetividade, dando-se início a um confronto entre o mundo interno e singular dos indivíduos (constituído por seus interesses, crenças e desejos) e o mundo externo e palpável do trabalho, composto por determinações e atividades nem sempre coincidentes às vontades, projetos e necessidades das pessoas (LANCMAN; SZNELWAR, 2011).

É fator de relevância a compreensão da organização prescrita do trabalho (metas, leis, regulamentos, regras, normas e procedimentos que descrevem como deve ser feita a execução das tarefas) e o trabalho real, vivo, que coloca o sujeito frente a uma situação de evidente fracasso se seguir fielmente o que está previsto, tendo em vista ser a realidade formada e estruturada por uma série de situações imprevisíveis no dia a dia, que ultrapassam o domínio técnico e científico. Por envolver muito mais do que apenas o cumprimento de regras préestabelecidas, o trabalho real requisita o uso da astúcia e demanda intenso funcionamento 
mental, por mais simples, mecânica ou manual que a ocupação seja, pois independentemente do ofício, as situações imprevistas acontecem e precisam ser resolvidas.

Constituindo-se exatamente de situações inesperadas que materializam o fracasso da prescrição, o trabalho vivo se manifesta afetivamente por meio do sofrimento, conduzindo inicialmente a uma experiência frustrante caracterizada pela impotência, para somente após a mobilização da personalidade e inteligência engajar o corpo e prover o desenvolvimento da reflexão, interpretação e reação diante do imprevisível, processo que ao término é capaz de provocar transformações e trazer alívio.

É por meio da transgressão das prescrições que a luta pela saúde mental no trabalho acontece, expressão do desejo de reelaborar aquele fazer. O sofrimento, ao impulsionar a criação de artimanhas e o emprego de afetos em direção à subversão dos impasses organizacionais, torna o sujeito mais habilidoso e competente, permitindo a ressignificação do sofrimento pela superação de eventos geradores de ansiedade, imprecisão e apreensão (LHUILIER, 2014). Assim, a busca e a superação dos impasses pautados no trabalho real permitem que o sofrimento seja compreendido não apenas como uma consequência lastimável expressa em patologias, e passe a se configurar, de maneira simultânea, em um estado de luta pela saúde e contra as forças que possam estar empurrando-o em direção ao adoecimento mental (DEJOURS, 2013).

Para dar um destino criativo ao sofrer através da sublimação é preciso um ambiente de confiança baseado na comunicação autêntica, no qual se reconheça a contribuição das invenções e macetes para o andamento do trabalho. A validação e adoção pelo coletivo dos procedimentos considerados eticamente mais apropriados promove o desenvolvimento da identidade e a realização profissional. Entretanto, quando o esforço em encontrar soluções é reiteradamente frustrado e não reconhecido, o sofrimento pode tomar a forma patogênica, comprometendo inclusive a própria construção da identidade profissional. Tal condição vai minando o uso da inteligência prática, impossibilitando a ressignificação do sofrimento e dando vazão ao uso de estratégias defensivas, que embora aparentemente adaptem os trabalhadores às situações ansiogênicas ao deixá-las inconscientes, podem, ao longo do tempo, desencadear a instalação de patologias sociais e adoecer (LANCMAN; SZNELWAR, 2011). 


\section{Método}

\section{Caracterização das instituições}

Fundamentado na Psicodinâmica do Trabalho, este estudo foi desenvolvido em 2015, em duas instituições governamentais de acolhimento localizadas no Pantanal Sul-matogrossense. A Casa de Acolhimento I, voltada para o atendimento de usuários de 0 a 17 anos e 11 meses, abrigava na época da pesquisa 20 crianças entre 0 e 11 anos e 10 adolescentes entre 12 e 17 anos, extrapolando a normativa de comportar até 20 acolhidos (BRASIL, 2009). Para a execução diária de cuidados sua equipe era composta por oito educadoras sociais e seis auxiliares, com duas auxiliares contratadas. A Casa de Acolhimento II atende usuários de 0 a 17 anos e 11 meses, e em abril de 2015 abrigava cinco crianças entre 6 e 11 anos e três adolescentes entre 12 e 17 anos.

A equipe responsável pelos cuidados cotidianos e imediatos era composta por seis educadoras sociais e três auxiliares, dentre as quais apenas três educadoras eram concursadas. Além de funcionarem 24 horas por dia e sete dias por semana, cada Casa contava com um repasse financeiro mensal para arcar com os gastos no valor de $\mathrm{R} \$ 6.500,00$ advindos do Governo Federal e R\$3.250,00 do Governo Estadual, sendo os gastos superiores a estes valores supridos pelo município.

\section{Participantes}

Foram convidados a participar todos os educadores sociais concursados e atuantes há pelo menos um ano em instituições governamentais, sendo excluídos os trabalhadores afastados e os não encontrados nos dias previamente definidos para a entrevista. Nove educadoras sociais integraram a pesquisa, todas mulheres, sete delas na faixa etária de 28 a 37 anos, sete com filhos, cinco apresentavam ensino superior completo, duas tinham superior incompleto e duas ensino médio completo. O tempo de serviço na instituição de seis entrevistadas variou de sete a nove anos, sete educadoras não tinham experiência prévia de trabalho com crianças e adolescentes, sete recebiam entre 1000 e 1500 reais/mês de salário (duas recebiam menos de 1000 reais/mês), e seis faziam turno de 12/36 horas, em períodos diurno e noturno.

\section{Instrumentos e coleta de dados}

Foi usado um questionário socioeconômico, contendo perguntas de cunho demográfico, relativas à formação acadêmica e ao trabalho das educadoras sociais, e uma entrevista 
individual semiestruturada, composta por perguntas sobre as atividades desenvolvidas junto aos acolhidos, como lidavam com as adversidades e a percepção de como o trabalho as afetava. Ambos os instrumentos foram aplicados de maneira individualizada e em sala reservada, com isolamento acústico e livre da interrupção de terceiros, tendo em vista o resguardo das informações concedidas pelas funcionárias. As entrevistas foram gravadas em áudio e o questionário socioeconômico foi auto aplicado, permanecendo a pesquisadora disponível no mesmo ambiente para sanar possíveis dúvidas de interpretação e compreensão que pudessem existir.

\section{Análise dos dados}

Os dados socioeconômicos do questionário foram analisados de forma descritiva, sempre no geral da amostra, e as entrevistas foram transcritas na íntegra e submetidas à Análise de Núcleo de Sentido (ANS), que pondera a qualidade e o sentido dos discursos a partir do destaque de conteúdos manifestos e latentes comuns apresentados nas verbalizações de maneira frequente e com semelhança quanto ao significado (MENDES, 2007). Após a leitura de cada entrevista e marcação das falas com temas psicológicos e semânticos representativos, estes foram agrupados para serem classificados em categorias.

\section{Considerações éticas}

Este estudo foi aprovado pelo Comitê de Ética em Pesquisa da Universidade Federal do Mato Grosso do Sul, com o CAAE: 42325915.9.0000.0021. Todas as participantes assinaram o Termo de Consentimento Livre e Esclarecido, e as informações coletadas foram analisadas em conjunto, sem distinção por lotação, para assegurar o sigilo da identidade.

\section{Resultados e discussão}

\section{O sofrimento do imprevisível}

A NOB-RH/SUAS estabelece que os educadores sociais devem suprir as demandas psicológicas e sociais de atenção, educação, apoio, proteção e cuidado das crianças e adolescentes atendidos, ponderando as suas necessidades individuais e favorecendo o desenvolvimento. Contudo, o grande número de crianças de tenra idade, com menos de um ano, 
demandava o atendimento prioritário da satisfação das necessidades básicas aos mais dependentes, incluindo alimentação, higienização e acalento dos bebês.

Muito dificil, porque eles [acolhidos] são muitos, e nós trabalhamos com duas monitoras basicamente para lidar com vinte, vinte e três crianças, principalmente bebê; bebê de colo quer isso aqui ó [referindo-se ao aconchego de uma criança que segurava no colo para adormecer], com cinco você vai fazer como? (PARTICIPANTE 2, entrevista individual, 18 de abril, 2015).

Apesar da afeição ser condição primeira para o desenvolvimento integral, devendo basear a relação profissionais-acolhidos (COSTA et al., 2018), a sobrecarga de trabalho impedia com que conseguissem suprir as dificuldades emocionais das crianças mais velhas: "Você tem que ficar cuidando o bebê e os pequenos, às vezes a gente acaba deixando de lado $o$ atendimento aos adolescentes, né" (PARTICIPANTE 3, entrevista individual, 23 de abril, 2015).

Para contemplarem a grande quantidade de tarefas a serem efetuadas junto a crianças e bebês, usavam e compartilhavam da estratégia de defesa da aceleração, viabilizando a adaptação a um trabalho sem possibilidade de ressignificação organizacional. A rapidez em fazer o serviço suscitava a percepção de um melhor desempenho e diminuía o torpor da frustração e impotência de não conseguirem mudar aspectos da política assistencial e da organização do trabalho deflagradores de sofrimento.

Embora a hiperatividade profissional mantivesse ocupado o aparelho psíquico, permitindo certo distanciamento afetivo aparentemente facilitador de escolhas e do modo de encaminharem suas práticas (LANCMAN; SZNELWAR, 2011), as educadoras continuavam afetadas pela tristeza dos bebês, das crianças e adolescentes. O sofrimento dos acolhidos as movimentava para suprirem as instituições com brinquedos, material para entretenimento e desenvolvimento, permitindo a aproximação do seu desejo por um trabalho realizador ao contexto organizacional insuficiente. Contudo, se por um lado a transgressão às prescrições convocava uma conduta ativa de enfrentamento ao sofrimento e de proteção à saúde mental, o constante uso da engenhosidade mantinha invisíveis à gestão municipal as demandas físicas, cognitivas e afetivas do serviço.

\section{Desvalorização e falta de reconhecimento de utilidade}

Influenciados pela ideologia essencialista, pais e familiares dos usuários sustentavam a natural emergência de habilidades e características maternais no desempenho dos cuidados e 
atenção, ignorando a construção social da identidade sexuada (KERGOAT, 2009) e das competências de devoção, renúncia e compaixão, ativadas no trabalho real, mediante o contato com o sofrimento alheio.

Mesmo com o poder de guarda restringido, mães e responsáveis não entendiam ou julgavam descabida a instalação da medida protetiva, menosprezando e desprestigiando o trabalho das educadoras, pois consideravam seus cuidados tão bons ou melhores do que os disponibilizados pela instituição. Por servirem como ponto de confluência das tensões entre familiares dos usuários e instituição, as educadoras sofriam com situações desagradáveis, vexatórias, eram atacadas e ofendidas: "Já houve casos de pais revoltados virem aqui na porta e achar que a culpa dos filhos estarem acolhidos são nossas, de serem agressivos, de chutar o portão, de querer nos agredir ai fora" (PARTICIPANTE 8, entrevista individual, 15 de maio, 2015).

Por estarem suscetíveis a diversas formas de agressão física e verbal, acusações levianas de maus-tratos aos acolhidos ou serem culpabilizadas pela desagregação familiar (COSTA et al., 2018), estabeleciam uma convivência distante com os pais e responsáveis, não existindo nesse elo qualquer indício de retribuição simbólica ou reconhecimento pelo trabalho prestado. Essa dificuldade relacional atrapalhava o vínculo entre instituição, educadora e pais, essencial para a construção de um ambiente protetivo propício para o retorno dos acolhidos ao lar de origem ou adotivo.

A falta de reconhecimento de utilidade por parte das coordenações também ocorria corriqueiramente, sendo visível o tratamento desigual dispensando às educadoras sociais, em comparação com o restante dos servidores que compunham as equipes técnicas das duas instituições. A desvalorização do ofício, cujo alicerce estava na própria falta de regulamentação da profissão, era vivenciada cotidianamente através da atribuição de múltiplas funções, por vezes nada condizentes com as suas incumbências reais, e pela constante retirada de autoridade e autonomia, causando constrangimento frente ao público atendido.

Eu falei com a criança [...] assim "tira essa camisa que não é pra ir... com essa camisa na escola"... ela pegou a criança... subiu com a criança... a criança mandou ela [...] e a criança desceu com a camisa... aí eu fiquei assim “quem sou eu pra falar o que então né”? (PARTICIPANTE 7, entrevista individual, 29 de abril, 2015).

Reforçando a cisão entre quem planejava e quem executava o serviço, o desmerecimento das opiniões e providências tomadas em relação a comportamentos indesejáveis apresentados pelos acolhidos dificultava a operacionalização e cumprimento dos afazeres. Os frequentes

RIAEE - Revista Ibero-Americana de Estudos em Educação, Araraquara, v. 15, n. esp. 3, p. 2396-2410, nov., 2020. E-ISSN: 1982-5587 
embaraços entre coordenação e educadoras ocorriam em qualquer lugar da instituição, não sendo raras as vezes em que tais situações eram presenciadas pelos usuários e culminavam em desrespeito e em episódios humilhantes, contribuindo para a desagregação das relações entre as profissionais e os acolhidos (LIMA, 2011). A sensação de desmoralização por não serem ouvidas nem reconhecidas em sua utilidade técnica aumentava as dúvidas acerca de como deveriam atuar profissionalmente.

\section{Afetividade no acolhimento-desacolhimento}

O momento do acolhimento, assinalado por rupturas e lutos diversos (TINOCO; FRANCO, 2011), caracterizava-se pelo aparecimento de preocupação e empatia com os que necessitavam de abrigo, cuidado e proteção. "A maioria chega assim, sujo, maltratado, revoltado, acuado, mudo, calado, com medo... Assim, eu fico triste, né" (PARTICIPANTE 7, entrevista individual, 29 de abril, 2015).

O conflito prescricional de "vincular-se afetivamente às crianças/adolescentes atendidos e contribuir para a construção de um ambiente familiar, evitando, porém, 'se apossar' da criança ou do adolescente" (BRASIL, 2009, p. 47) trazia à tona sentimentos contraditórios que transitavam entre o sentimento de abandono até a sensação de dever cumprido: "Eu fico feliz porque eles estão indo de volta para a família, porque acho que toda criança tem que estar com a família, mas ao mesmo tempo a gente acaba se apegando, então existe uma pontinha de tristeza" (PARTICIPANTE 5, entrevista individual, 28 de abril, 2015).

A perda da posição afetuosa, em razão da adoção ou da devolução do acolhido à sua família de origem, não recebia atenção, supervisão ou apoio da equipe técnica, constatando-se a dificuldade institucional em preparar as educadoras para lidarem com o momento de desligamento, o que seria de grande valia para superarem o luto e ajustarem suas práticas laborais à identidade profissional.

As trabalhadoras não eram consultadas no processo de desligamento ou adoção, embora pudessem contribuir para esse momento, notadamente marcado por recordações de abandono, ressentimento e novas perspectivas sobre relações parentais (COSTA et al., 2018). A tristeza e a impotência foram também reportadas nas recorrentes situações de desrespeito e agressividade por parte dos adolescentes que se rebelavam ao terem de seguir novos hábitos, horários e regras (CAVAlCANTE; CORRÊA, 2012; LEMOS et al., 2014): “É muito dificil lidar com os palavrões que eles dizem, ofendem com muitos xingamentos, quando a gente fala não pra 
alguma coisa pra eles, eles não gostam e já saem batendo porta, joga cadeira" (PARTICIPANTE 3, entrevista individual, 23 de abril, 2015).

Não se pode desconsiderar que a desvalorização profissional presenciada na instituição, aliada à escassa atenção deferida aos adolescentes, influenciava na construção de uma relação fragilizada entre as educadoras e acolhidos, ampliando a chance de serem ofendidas ao ditarem limites e tentarem impor sua autoridade.

\section{A identidade profissional propulsora de realização}

Compartilhar com o grupo as soluções encontradas diante dos impedimentos organizacionais ocasionava certa sensação de apoio e maior segurança nas situações inesperadas, já que apenas duas funcionárias relataram experiência profissional anterior com crianças e adolescentes, e outras duas tinham adquirido noções sobre desenvolvimento após ingressarem em cursos universitários. A apropriação e a transformação da inventividade em saber-fazer diário validava o esforço individual e o investimento da personalidade em ação no rebatimento das constrições sociais e materiais, criando um ambiente de cooperação e de confiança propício à mobilização subjetiva e à retomada do sentido do trabalho.

Mesmo sendo-lhes negado o reconhecimento da utilidade, as educadoras sociais demonstraram identificação com o trabalho socioeducativo, sentindo orgulho pelo êxito nas tarefas de ensino, cuidado e educação dos acolhidos. "A gente vê que eles estão aprendendo a ter respeito, a ter boas maneiras; eu vejo que aquilo é resultado do nosso trabalho, porque não tiveram isso em casa, né" (PARTICIPANTE 1, entrevista individual, 16 de abril, 2015).

Ensinar o respeito e boas maneiras, acompanhar a situação escolar, prover cuidados, construir vínculos por meio de diálogo e de convivência diária desejável foram atividades mencionadas como geradoras de sensações positivas e satisfação. Quando suas intervenções colaboravam para a melhoria da qualidade de vida dos usuários se sentiam orgulhosas e realizadas.

\section{Considerações finais}

As educadoras sociais não recebiam capacitação para lidar com as dificuldades enfrentadas no contato com os acolhidos, sendo que entender as consequências das experiências de violações e rupturas, produtoras de sentimentos de desamparo, incerteza, descontentamento e culpa oportunizaria o estabelecimento de um atendimento condescendente diante das 
legítimas necessidades dos usuários. Muito embora a normatização para o serviço indicasse a indispensabilidade de preparo para atuação no fortalecimento dos vínculos familiares entre crianças e famílias de origem, a política de pessoal não provia orientações, apoio ou supervisões nas ações de solidificação das relações fragilizadas entre acolhidos e a família de origem, nem fornecia conhecimentos sobre a garantia de proteção e de direitos às crianças e adolescentes, desenvolvimento infanto-juvenil, funcionamento dos serviços socioassistenciais ou procedimentos para adoção (BRASIL, 2009).

Logo, para cumprirem com suas funções, as trabalhadoras acessavam experiências particulares socioafetivas, que por serem consideradas naturalmente femininas justificavam a desobrigação da gestão em ofertar especialização e formação. A mobilização subjetiva frente ao flagelo de crianças e adolescentes conduzia ao empenho e engajamento para superarem as falhas organizacionais e concretizarem satisfatoriamente as ações de reparo psíquico e físico dos acolhidos.

A impossibilidade de modificarem a organização do trabalho, caracterizada pela sobrecarga de abrigados e realização de variadas atividades, conduzia à autoaceleração. Se o uso da estratégia defensiva permitia uma frágil adaptação às exigências impostas, a insensibilidade derivada da rapidez imposta impactava na qualidade da atenção deferida e na percepção das necessidades de intervenção, sendo capaz de prejudicar a reconstrução dos laços afetivos e o desenvolvimento integral dos usuários (CRUZ; DIAS; PEDROSO, 2014).

O uso de defesas para colocar em prática o serviço evidenciou que a organização do trabalho vivenciada não só dificultava o desempenho da ocupação como também acirrava o sofrimento daquele fazer. Como as educadoras não contavam com um espaço articulador de ideias e de experiências, o desgaste emocional se mantinha, dificultando a concretização de modificações politizadas imbricadas na ressignificação do trabalho para o alcance de prazer e realização.

Para além da regulamentação legal da ocupação, Guará (2006) aponta a necessária assimilação da identidade socioeducadora por parte da instituição, da equipe e dos acolhidos para que o acolhimento seja pautado pela educação, proteção, cuidado e apoio, com vistas à inserção social plena e novos projetos de futuro aos acolhidos (FERREIRA; SANTOS, 2019). Embora tal construção se faça a partir da reflexão das práticas, relações e episódios cotidianos vivenciados pelas educadoras sociais, não houve possibilidade de construir nas Casas de Acolhimento um ambiente de ponderação e deliberação. A comunhão das dificuldades encontradas no trabalho real e das táticas de transcendê-las, em um espaço que priorize o reconhecimento da beleza e da utilidade do cuidar e do educar, pode favorecer a composição 
do coletivo, a partir da afirmação de uma atuação ética e técnica constituinte da identidade profissional.

AGRADECIMENTOS: Esta pesquisa contou com o apoio da Fundação Universidade Federal de Mato Grosso do Sul.

\section{REFERÊNCIAS}

BRASIL. Lei n. 8.069, de 13 de julho de 1990. Dispõe sobre o Estatuto da Criança e do Adolescente e dá outras providências. Brasília, DF: Diário Oficial da República Federativa do Brasil, 1990. Disponível em:

http://www.planalto.gov.br/ccivil_03/LEIS/L8069.htm\#art266. Acesso em: 29 ago. 2020.

BRASIL. Ministério do Desenvolvimento Social e Combate à Fome, Secretaria Nacional de Assistência Social. Norma Operacional Básica de Recursos Humanos do SUAS (NOBRH/SUAS). Brasília, DF. 2006. Disponível em: https://docs.google.com/ 2006.viewer?a=v\&pid=sites\&srcid=ZGVmYXVsdGRvbWFpbnxjb25ncmVzc29yZWdpb25h bGRvc3NvY2lvbG9nb3N8Z3g6NzVhMTgyMzZlZWY2NjNhNg. Acesso em: 29 ago. 2020.

BRASIL. Conselho Nacional dos Direitos da Criança e do Adolescente. Conselho Nacional de Assistência Social. Orientações técnicas: serviços de acolhimento para crianças e adolescentes. Brasília, DF. 2009. Disponível em: http://acolhimentoemrede.org.br/site/wpcontent/uploads/2014/04/Orienta\%C3\%A7\%C3\%B5es-T\%C3\%A9cnicas.pdf. Acesso em: 29 ago. 2020.

CAVALCANTE, L. I. C.; CORREA, L. S. Perfil e trajetória de educadores em instituição de acolhimento infantil. Cad. Pesqui., São Paulo, v. 42, n. 146, p. 494-517, ago. 2012. DOI: https://doi.org/10.1590/S0100-15742012000200010

COSTA, C. F.; SANTOS, T. F.; SANTOS, V. S.; LIMA, L. A. G. Entre a instituição e o lar: uma odisseia com educadores. Pesqui. prát. psicossociais, São João del-Rei, v. 13, n. 1, p. 115, abr. 2018. Disponível em:

http://pepsic.bvsalud.org/scielo.php?script=sci_arttext\&pid=S1809-

$89082018000100004 \& \operatorname{lng}=$ pt\&nrm=iso. Acessos em: 28 ago. 2020.

CRUZ, E. J. S.; DIAS, G. B.; PEDROSO, J. S. Estudo do "Ages and Stages Questionnaires" com cuidadores de crianças institucionalizadas. Psico-USF, Itatiba, v. 19, n. 3, p. 411-420, dez. 2014. DOI: https://doi.org/10.1590/1413-82712014019003004

DEJOURS, C. A sublimação, entre sofrimento e prazer no trabalho. Revista Portuguesa de Psicanálise, v. 33, n. 2, p. 9-28, 2013. Disponível em: http://docplayer.com.br/24920304-Asublimacao-entre-sofrimento-e-prazer-no-trabalho-1.html. Acesso em: 29 ago. 2020.

FERREIRA, D. C. R. R. F.; SANTOS, A. R. J. A educação não formal e sua interface com a pedagogia social: conceito, contexto e proposições da formação do sujeito cidadão. Revista 
Ibero-Americana de Estudos em Educação, Araraquara, v. 14, n. 4, p. 2275-2286, 2019. DOI: https://doi.org/10.21723/riaee.v14i4.11975

GOLIN, G.; BENETTI, S. P. C. Acolhimento precoce e o vínculo na institucionalização. Psicologia: Teoria e Pesquisa, Brasília, v. 29, n. 3, p.241-248, set. 2013. DOI: https://doi.org/10.1590/S0102-37722013000300001

GUARÁ, I. M. F. R. Abrigo: comunidade de acolhida e socioeducação. In: BAPTISTA, M. V. (Coord.). Abrigo: comunidade de acolhida e socioeducação. São Paulo: Instituto Camargo Corrêa, 2006. p. 63-72.

HALPERN, E. E.; LEITE, L. M. C.; MORAES, M. C. M. B. Seleção, capacitação e formação da equipe de profissionais dos abrigos: o hiato entre o prescrito e o real. Trab. educ. saúde, Rio de Janeiro, v. 13, supl. 1, p. 91-113, 2015. DOI: https://doi.org/10.1590/1981-7746sip00033

KERGOAT, D. Divisão sexual do trabalho e relações sociais de sexo. In: HIRATA, H.; LABORIE, F.; LE DOARÉ, H.; SENOTIER, D. (Org.). Dicionário crítico do feminismo. Trad. Vivian Aranha Saboia. São Paulo: Editora Unesp, 2009. p. 67-75.

LANCMAN, S.; SZNELWAR, L. I. (Org.). Christophe Dejours: da psicopatologia à psicodinâmica do trabalho. 3. ed. Brasília: Paralelo 15, 2011.

LEMOS, A. G. A.; MORAES, M. M. B.; ALVES, D. G.; HALPERN, E. E.; LEITE, L. C. Evasão nas unidades de acolhimento: discutindo seus significados. Psicol. Soc., Belo Horizonte, v. 26, n. 3, p. 594-602, dez. 2014. DOI: https://doi.org/10.1590/S010271822014000300008

LHUILIER, D. Introdução à psicossociologia do trabalho. Cad. psicol. soc. trab., São Paulo, v. 17, n. esp., p. 5-20, jun. 2014. DOI: http://dx.doi.org/10.11606/issn.1981-0490.v17ispe1p519

LIMA, S. C. C. Coletivo de trabalho e reconhecimento: uma análise psicodinâmica dos cuidadores sociais. Orientadora: Ana Magnólia Mendes. 2011. 220 f. Tese (Doutorado em Psicologia Social, do Trabalho e das Organizações) - Universidade de Brasília, Brasília, 2011.

MANICA, L. E. A educação profissional formal e não formal das pessoas com deficiência no Brasil. Revista Ibero-Americana de Estudos em Educação, Araraquara, v. 12, n. 4, p. 19982023, out./dez. 2017. DOI: https://doi.org/10.21723/riaee.v12.n4.out./dez.2017.9320

MEDEIROS, B. C. D.; MARTINS, J. B. O Estabelecimento de vínculos entre cuidadores e crianças no contexto das instituições de acolhimento: um estudo teórico. Psicol. cienc. prof., Brasília, v. 38, n. 1, p. 74-87, mar. 2018. DOI: https://doi.org/10.1590/1982-3703002882017

MENDES, A. M. Pesquisa em psicodinâmica do trabalho: a clínica do trabalho. In: MENDES, A. M. (Org.). Psicodinâmica do trabalho: teoria, método e pesquisas. São Paulo: Casa do Psicólogo, 2007. p. 65-87.

PEREIRA, A. A profissionalidade do educador social frente a regulamentação profissional da educação social: as disputas em torno do projeto de lei 5346/2009. Revista Ibero-Americana 
de Estudos em Educação, Araraquara, v. 11, n. 3, p. 1294-1317, 2016. DOI: https://doi.org/10.21723/riaee.v11.n3.6041

TEIXEIRA, P. A. S.; VILLACHAN-LYRA, P. Sentidos de desacolhimento de mães sociais dos sistemas de casas lares. Psicol. Soc., Belo Horizonte, v. 27, n. 1, p. 199-210, abr. 2015. DOI: https://doi.org/10.1590/1807-03102015v27n1p199

TINOCO, V.; FRANCO, M. H. P. O luto em instituições de abrigamento de crianças. Estud. psicol., Campinas, v. 28, n. 4, p. 427-434, dez. 2011. DOI: https://doi.org/10.1590/1807$03102015 \mathrm{v} 27 \mathrm{n} 1 \mathrm{p} 199$

\section{Como referenciar este artigo}

BASSOLI, E. N.; FIGUEIREDO, V. C. N. Desafios do trabalho de educadoras sociais em casas de acolhimento. Revista Ibero-Americana de Estudos em Educação, Araraquara, v. 15, n. esp. 3, p. 2396-2410, nov., 2020. E-ISSN: 1982-5587. DOI: https://doi.org/10.21723/riaee.v15iesp3.14448

Submetido em: 20/07/2020

Revisões requeridas em: 30/08/2020

Aprovado em: 29/09/2020

Publicado em: 30/10/2020 